\title{
Causes of School Bullying
}

\section{Empirical Test of a General Theory of Crime, Differential Association Theory, and General Strain Theory}

Byongook Moon

University of Texas at San Antonio

Hye-Won Hwang

Chongju University, Republic of Korea

John D. McCluskey

University of Texas at San Antonio

A growing number of studies indicate the ubiquity of school bullying: It is a global concern, regardless of cultural differences. Little previous research has examined whether leading criminological theories can explain bullying, despite the commonality between bullying and delinquency. The current investigation uses longitudinal data on 655 Korean youth, in three schools, to examine the applicability of leading criminological theories (general theory of crime, differential association theory, and general strain theory) in explaining school bullying. Overall, our findings indicate limited support for the generality of these three leading criminological theories in explaining the etiology of bullying. However, the findings show the significant effects of school-generated strains (teachers' physical and emotional punishment and examination related strain) on bullying. Directions for future research and policy implications of these findings are discussed.

Keywords: bullying; Korean youth; general theory of crime; differential association theory; general strain theory

\footnotetext{
Chool bullying has recently gained near-universal attention among researchers, media, school authorities, and parents concerned about students' well-being and safety (Bosworth, Espelage, \& Simon, 1999; Ma, 2001; Olweus, 1978; Salmivalli, Lagerspetz, Bjorkqvist, Osterman, \& Kaukiainen, 1996; Siann, Callaghan, Glissov, Lockhart, \& Rawson, 1994; Smith \& Brian, 2000). A significant number of studies have been conducted in multiple countries to examine the prevalence of bullying and physical,
} 
psychological, and emotional harm to victims (Bosworth et al., 1999; Greenbaum, Turner, \& Stephens, 1988; Lowenstein, 1978; Olweus, 1978, 1991; Rigby \& Slee, 1991; Salmivalli et al., 1996; Salmon, James, Cassidy, \& Javaloyes, 2000). Overall, these studies support the ubiquity of school bullying, regardless of cultural differences. Additionally, research indicates that bullied students suffer physical and psychological problems such as depression, anxiety, suicide, school dropout, school avoidance, and learning problems (Greenbaum et al., 1988; Olweus, 1993; Rigby \& Slee, 1999; Salmon et al., 2000).

In light of the extensive study of this topic, it is surprising that few studies have attempted to systematically examine factors affecting bullying (see Bosworth et al., 1999). Perhaps most important is the dearth of research engaging in extensive empirical tests to determine whether leading criminological theories can explain bullying. In the current study, we attempt to address these limitations by analyzing longitudinal data collected on a panel of Korean youth. We use three leading criminological theories with a general scope - a general theory of crime, differential association theory, and general strain theory (GST) — as frameworks for explaining the causes of bullying.

This is important research from at least three perspectives. First, it will serve to bridge criminology and its typical emphasis on serious misbehavior with the (arguably) more mundane but pervasive behavior of school bullying. Second, it will explore the fit of general criminological theory in an international context, which is an area where criminology must expand its empirical inquiries. Finally, this investigation will open the door for further study of this topic as we necessarily will leave more questions, and directions for future research, than answers in our wake.

Three areas that must be introduced by this research include definitions of the phenomenon of school bullying, whether it is, indeed, a universal phenomenon, and the extent of the consequences of this activity. Below we will address these threshold issues as well as discuss bullying in the specific context of Korea. We will also briefly introduce important explanatory concepts from the three aforementioned theories and engage in empirical testing to assess the overall fit of those general theories of deviance to the phenomenon of school bullying.

\section{The Definition, Prevalence, and Negative Consequences of Bullying}

School bullying has been studied extensively in internationally and culturally different settings, but there is no unified definition (Bosworth et al., 
1999; Peterson \& Ray, 2006; Siann et al., 1994). However, the common theme among various definitions of bullying is that bullying comprises physical and verbal attacks and harassment directed at a victim(s) by one student or a group of students over an extensive period of time (Espelage \& Swearer, 2003).

Olweus $(1978,1993,1994)$ conducted the first systematic research on bullying. With a sample of Norwegian and Swedish students, he found that a significant number of students in these countries are affected by school bullying. Approximately $7 \%$ of Scandinavian students in the sample engaged in school bullying, and between 5\% and $15 \%$ of students in various grades reported being bullied. Subsequently, numerous studies on school bullying were conducted in various countries (i.e., Austria, Canada, China, England, Finland, Italy, Japan, South Korea, and the United States) to understand the prevalence of bullying, factors associated with bullying, negative consequences, and prevention mechanisms. These studies consistently indicate that school bullying is a global phenomenon. For example, Nansel et al. (2001) studied a representative sample of U.S. youth in 6th through 10 th grade and found that approximately $13 \%$ of those in the sample engaged in bullying. Wong (2004) analyzed a sample of 7,025 students attending primary and secondary schools in Hong Kong and found that $17 \%$ of students at secondary schools and $23 \%$ of those at primary schools engaged in physical bullying such as slapping, fist-fighting, hitting, and assaulting fellow students. Baldry and Farrington (2000) with a sample of 238 middle school students in Italy found that more than half of students (53\%) reported bullying others during the past 3 months. It is not known whether the prevalence of bullying for different countries actually varies or is due to different definitions and methodologies (see Espelage \& Swearer, 2003). Nevertheless, the ubiquity of bullying behavior seems unquestionable.

This body of research also indicates that bullies are more likely to engage in antisocial and criminal behaviors in their adolescence and adulthood (Batsche \& Knoff, 1994; Farrington, 1991; Loeber \& Dishion, 1983; Olweus, 1993). For example, a longitudinal study by Olweus (1993) showed that $60 \%$ of bullies in Grades 6 to 9 were found to have a history of at least one conviction in their 20 s, and approximately $40 \%$ had a history of multiple convictions. Similarly, Farrington (1991) found a positive relationship between bullying during childhood and criminal behaviors in adulthood. Longitudinal research indicates that those who bullied others during the childhood were more likely to engage in criminal behaviors as adults. 


\section{School Bullying in the Korean Context}

In recent years, school violence in South Korea, especially school bullying, has been exposed as a serious school and social problem (BBC, 2007; Kim, Koh, \& Leventhal, 2005). A variety of studies have examined the prevalence of school bullying and its negative consequences in South Korea (Kim, Kim, \& Jung, 2001; Korean Educational Development Institute, 1998; Korean Institute of Criminal Justice Policy, 1997; National Youth Commission, 2003; Seo \& Kim, 2004; Yang, 2004). Consistent with findings in Western countries, these studies indicate a high prevalence of school bullying in South Korea. For example, the National Youth Commission (2003), sampling 14,638 elementary, middle, and high school Korean students, found that approximately $26 \%$ of respondents experienced school bullying. Relatively few studies sampling Korean youth examined the effects of individual and school factors on school bullying (Yang, 2004). Limited studies (i.e., Seo \& Kim, 2004) indicate that bullies are more likely to show a high level of aggression and impulsivity and associate with delinquent peers.

Despite a high prevalence of school bullying and negative consequences to both victims and bullies in South Korea, there is little evidence that schools and teachers have comprehended the seriousness of the issue, developed any systematic plan for preventing school bullying, or provided any counseling services to those involved in school bullying. For example, the Korean Educational Development Institute (1998) found a significant gap in the perception of the existence of bullying between teachers and students. The results show that only $20 \%$ of teachers reported the existence of bullying in their classes, whereas $60 \%$ of students indicated the existence of bullying. S. G. Lee (2005) also found that school authorities tend to deny the existence of school bullying or underreport the prevalence of school bullying. Overall, these findings indicate that school authorities and teachers do not give enough attention to school bullying or are not fully aware of its consequences.

\section{Three Theoretical Frameworks for Understanding School Bullying}

Overall, the magnitude and consequences of bullying appear to merit a larger research agenda. That research would benefit greatly from theories already applied to criminal behavior. The current investigation fills this gap in the literature by assessing the fit of criminological theories to the school 
bullying phenomenon. Below we review three criminological theories briefly and describe how these theories provide credible explanations of school bullying.

\section{Low Self-Control and Bullying}

According to Gottfredson and Hirschi (1990, pp. 89-90), low self-control is the main source of criminal behaviors and behaviors analogous to crime. Individuals with low self-control are more likely to seek immediate gratification, to be physically active, to be insensitive to others, and to possess limited cognitive and academic skills. Gottfredson and Hirschi also argued that effective parental practices (i.e., monitoring, recognition of deviant behaviors, and punishment of deviant behavior) have a significant effect on the development of self-control. Overall, parenting practices are hypothesized to have a significant effect on child's self-control, which in turn affects deviant and criminal behaviors.

Despite the recent development of the theory, a large body of empirical research has generally confirmed the existence of a significant positive relationship between low self-control and deviant behaviors (Baron, 2003; Grasmick, Tittle, Bursik, \& Arneklev, 1993; Hay, 2001; LaGrange \& Silverman, 1999; Pratt \& Cullen, 2000). The research findings can be generally summarized as indicating that individuals with low self-control are more likely to engage in criminal behaviors and behaviors analogous to crime.

Several studies examined the relationship between bullying and low self-control or analogous concepts. A study by Olweus (1991) indicated there is a significant and positive relationship between impulsivity and bullying behavior. Other studies (e.g., Endresen \& Olweus, 2001; Olweus, 1994; Slee \& Rigby, 1993) also found that bullies are more likely to lack empathy for others. Overall, these findings indicate that bullies are more likely to be impulsive, to lack empathy for others, and to be easily provoked, all consistent with low self-control.

\section{Differential Association Theory and Bullying}

Differential association theory (Sutherland, 1947) posits that delinquent and criminal behaviors are learned in a fashion similar to law-abiding behaviors. Sutherland (1947) argued that individuals are more likely to engage in delinquent and antisocial behaviors when they associate with delinquent peers or deviant parents. By associating with intimates (i.e., parents and friends) who exhibit antisocial behaviors and/or have favorable 
attitudes toward the violation of laws, individuals learn techniques of committing delinquent or criminal behaviors, as well as motives and attitudes that serve to promote criminal and antisocial behaviors. Sutherland also argued that the effects of associations on individuals vary depending on frequency, duration, priority, and intensity.

There is ample evidence of strong criminogenic effect of association with delinquent peers on delinquency and crime (Elliott \& Menard, 1996; Simons, Wu, Conger, \& Lorenz, 1994; Warr, 2005). Research has consistently shown that juveniles who associate with delinquent peers are more likely to engage in antisocial and delinquent behaviors. Studies also indicate a significant relationship between positive attitudes toward the use of violence and delinquency. Juveniles who report positive beliefs about violence are more likely to engage in antisocial and criminal behaviors.

Though the extant bullying research did not specifically adopt differential association theory as a theoretical framework in explaining bullying, several studies have examined the relationship between delinquent peer association, attitude toward violence and bullying (e.g., Espelage, Bosworth, \& Simon, 2000; Pepler \& Craig, 1995). As expected, results indicate that juveniles who associate with bullies and/or report positive attitudes toward the use of violence are more likely to engage in bullying. Moreover, Pepler and Craig (1995), using a remote audiovisual observation method, found that a group of children collectively engage in bullying as aggressors, rather than as an individual child engaging in bullying. In sum, the findings from the extant bullying research indicate that differential association theory is a viable explanation of the phenomenon.

\section{General Strain Theory and Bullying}

The key proposition of GST is that strains cause delinquency. Criticizing a narrow concept of strain defined by classical strain theory, Agnew (1992) expanded the sources of strain and grouped them into three categories: (a) the failure to achieve positively valued goals, (b) the possible or actual loss of positively valued stimuli-stressful life events (i.e., parental loss), and (c) the presentation of noxious stimuli to individuals (i.e., emotional and physical abuse, criminal victimization, or discrimination). The other main proposition of GST is that strains create negative emotions (i.e., anger, anxiety, depression), which in turn influence delinquency. According to GST (Agnew, 1992), individuals experience negative emotions, especially anger, when they are treated unjustly and unfairly or exposed to negative stimuli. As a way to correct a situation or alleviate their negative emotions, strained individuals may commit delinquent behaviors. 
A large body of empirical findings consistently support the key propositions of GST, showing that individuals exposed to various types of strain are more likely to engage in delinquent behaviors (Agnew, Brezina, Wright, \& Cullen, 2002; Aseltine, Gore, \& Gordon, 2000; Mazerolle \& Maahs, 2000; Mazerolle \& Piquero, 1997; Moon \& Morash, 2004; Piquero \& Sealock, 2000). Consistent with the prediction of GST, several studies have found that negative emotions, especially anger, moderately mediate the connection of strain and delinquency (Mazerolle \& Piquero, 1997; Mazerolle, Piquero, \& Capowich, 2003; Piquero \& Sealock, 2000).

The applicability of elements of GST to the bullying phenomenon is suggested by the findings from several studies. For example, Browne and Falshaw (1996) analyzed a sample of youth placed at a youth treatment service and found that bullies were more likely to suffer childhood physical and emotional abuse, as indicated by their placement on the child protection register. Other studies with diverse samples (Batsche \& Knoff, 1994; Espelage et al., 2000; Olweus, 1993) revealed that youths' experience of physical punishment, maltreatment, and rejection by parents, peers, and teachers are significantly related to bullying. In addition, some studies (Bosworth et al., 1999; Espelage et al., 2000) indicate that anger has a significant positive effect on bullying. Overall, these findings would be consistent with considering GST as an explanation because they indicate that individuals who experienced physical/emotional abuse, maltreatment, rejection and/or anger are more likely to engage in bullying.

There is a commonality between delinquency and bullying, inasmuch as many physically aggressive bullying acts (i.e., hitting, kicking, and slapping other students) would be considered within the universe of delinquent behavior. However, bullying is different from delinquency in one important aspect: Some bullying behaviors, which are related to emotional and psychological harms (i.e., isolating, intimidating, teasing, and spreading rumors), are not typically considered as delinquency (Wong, 2004). Given this distinction, further research is necessary to examine the etiology of school bullying and whether dominant criminological theories that were originally developed to explain delinquency and criminal behaviors can adequately explain bullying. The current study attempts to fill this gap.

\section{Method}

\section{Sample}

The data for this research were from the first two waves of an ongoing longitudinal study supported by the Korea Research Foundation Grant 
funded by the Korean Government (MOEHRD). ${ }^{1}$ The research was designed with the explicit intent of examining various factors affecting delinquency among Korean youths. The first and second waves of the longitudinal data were collected at 1-year intervals from a panel of South Korean middle school students in 2005 and 2006. For each school, those students whose parents allowed them to participate in the research in written formats were asked to voluntarily participate in answering the questionnaire.

Three middle schools located in three different cities (Incheon, Daegu, and Cheongju) were selected for inclusion. South Korea is one of the most densely populated countries in the world, and a majority of the population resides in metropolitan areas, especially in the northern and southern parts of the country (U.S. Department of State, 2007). Therefore, two metropolitan cities, Incheon and Daegu, were selected as research sites. Incheon is located in a northern part of South Korea and has a population of 2.6 million, and Daegu, a metropolitan city with a population of 2.5 million, is located in the southern part of the country. To include students not residing in and around metropolitan area, Cheongju, a medium-sized city with a population of approximately 600,000 , was selected. The city is located in the central region of the country, which is less populated, compared to the northern and southern parts of the country.

With regard to the number of new students entering middle schools, Daegu and Incheon had 38,055 and 40,949 in 2006 (Korean Statistical Information Service, 2007b). These numbers are similar to the number of new middle students in other metropolitan cities such as Busan. In Chungchung Namdo Province, where Cheongju is located, 25,999 students entered middle schools in 2006. This number is similar to the number of new students in other main provinces such as Chunra Namdo (25,426 new students in 2006). Poverty rates for the two metropolitan cities and Cheongju are not dramatically different from the rates for other metropolitan cities and provinces. For example, Incheon and Daegu were ranked as having the 4th and 6th lowest poverty rates out of 16 metropolitan cities and provinces; and Chungcheongbukdo Province, where Cheongju is located, was ranked 9th (HanKokilbo, 2007). In 2005, 4,677 delinquency cases were reported and investigated by the police in Daegu (Korean Statistical Information Service, 2007a). In Incheon, a similar number of juvenile delinquency cases $(4,902)$ were recorded as investigated by the police in 2004 (Incheon Statistical Yearbook, 2005). The police investigated 1,300 juvenile delinquency cases in Cheongju in 2001 (Cheongju Statistical Yearbook, 2005) and other medium-sized cities such as Gumi (a population of around 400,000) had similar numbers of juvenile cases (Gumi Statistical Yearbook, 2005). There 
appears to be no remarkable variation in the number of officially recorded delinquency cases investigated in the areas sampled.

It is likely that the sample used in the current study may not represent middle school students in smaller cities and rural areas. However, the urbanization rate in South Korea is extremely high (around 82\%), so only a small proportion of juveniles reside in rural areas (Korea Times, 2005).

A school in each city was randomly selected from the list of middle schools: There were 90 middle schools in Incheon, 108 middle schools in Daegu, and 30 middle schools in Cheongju. In contrast to the United States, there is little variation among middle schools in terms of the quality of education, academic curriculum, and students' academic achievement in South Korea. Secondary education before high school is free and compulsory and there is no entrance examination for particular schools (Ministry of Education and Human Resources Development, 2007). South Korea has adopted a national curriculum structure, closely supervised and controlled by the Ministry of Education and Human Resources Development (central government). Typically, there are no advanced programs and no examinations testing students' qualification to move to the next grade (i.e., there is automatic advancement in primary and secondary education). To become a primary or secondary school teacher at a public school, candidates with a baccalaureate degree in education need to pass a highly competitive national examination, and those who passed the examination are randomly assigned to public schools. Moreover, in South Korea, there is little difference between public and private middle schools: Both use the same academic curriculum, students pay the same tuition, and both are tightly supervised by the central government. Regardless of their academic achievement in elementary schools, students are assigned to middle schools (including private schools) nearest their homes (Ministry of Education and Human Resources Development, 2007). As mentioned above, South Korea is densely populated, geographically small (the size of the state of Indiana with $70 \%$ mountainous terrain), and is ethnically homogeneous. There is little reason to expect that the youth in the sample would differ from the youth in the general population, except that rural youths are not represented.

Cooperation of administrators and teachers in each school was obtained to administer the survey. The purpose of the project was then announced and explained to all students. To maximize accuracy of the responses, researchers distributed and collected questionnaires at all three schools. Students were allowed 1 hour to complete the questionnaire. 
In the first wave (2005), the students in eighth grade (generally 13 years old) in each school were asked to participate. Among 900 questionnaires distributed to students in the three schools, 817 questionnaires were collected. However, 30 questionnaires were incomplete and thus discarded. Overall, 787 students completed the questionnaire yielding a response rate of $87 \%$. In the second wave (collected in 2006), 664 students of the original study participated and completed the questionnaires and a total of 655 individuals had complete data for the current analyses. The attrition rate of participants from the first wave to the second wave data collection was $16 \%$. To examine any differences between students who continued to participate in the study and those who failed to participate in the second wave data collection, the means of main variables were compared for the main variables under study. There were no significant differences between the two groups in the level of main variables (i.e., self control, strains, association with delinquent peers, attitude toward the use of violence, negative emotions, and bullying) at Wave 1.

\section{Independent Variables}

All of the theoretically derived independent variables discussed below were measured at Wave 1 to ensure proper temporal ordering with the outcome of bullying observed at Wave 2 (see Table 1).

\section{Low Self-Control}

The self-control scale is derived from the work of Grasmick et al. (1993) and consisted of 24 items. Grasmick et al. used these 24 items to measure six dimensions of low self-control described by Gottfredson and Hirschi (1990). These included impulsiveness, preference for simple tasks, risk seeking, preference for physical activities, self-centeredness, and volatile temper. The result of a principal components factor analysis, using a varimax rotation method, indicated six factors with eigenvalues ranging from 5.0 to 1.3. Consistent with previous studies (Grasmick et al., 1993; Mitchell \& MacKenzie, 2006), we considered the substantial difference in eigenvalues between the first (5.0) and second factors (2.7) as indicating a one-dimensional aspect of self-control. The response options for the scale ranged from 1 (strongly disagree) to 4 (strongly agree). The scale was coded so that a higher score indicates a lower level of self-control (Cronbach's alpha $=.81)$.

\section{The Association With Delinquent Peers and the Legitimacy of Violence}

The association with delinquent peers scale was adapted from the study by Mazerolle and Maahs (2000) and measured at Wave 1. Its purpose is to 
Table 1

Descriptive Statistics of Independent and Dependent Variables

\begin{tabular}{|c|c|c|c|c|}
\hline Variable & Mean & $S D$ & Minimum & Maximum \\
\hline Gender: female $=0$, male $=1$ & 0.38 & 0.49 & 0 & 1 \\
\hline $\begin{array}{l}\text { Height: low height group }=1 \text {, } \\
\text { medium height group }=2, \\
\text { high height group }=3\end{array}$ & 2.00 & 0.54 & 1 & 3 \\
\hline $\begin{array}{l}\text { Grade (academic achievement): } \\
\text { high grade group }=1, \\
\text { medium grade group }=2, \\
\text { low grade group }=3\end{array}$ & 1.88 & 0.73 & 1 & 3 \\
\hline $\begin{array}{l}\text { Income: low income group }=1 \text {, } \\
\text { medium income group }=2, \\
\text { high income group }=3\end{array}$ & 1.92 & 0.59 & 1 & 3 \\
\hline Low-self control & 54.38 & 10.43 & 24 & 96 \\
\hline Legitimacy of violence & 8.64 & 3.66 & 5 & 20 \\
\hline Association with delinquent peers & 2.38 & 3.42 & 0 & 28 \\
\hline Family conflict & 2.59 & 2.01 & 0 & 9 \\
\hline Parental punishment & 1.97 & 2.58 & 0 & 15 \\
\hline Teachers' punishment & 1.66 & 2.70 & 0 & 16 \\
\hline Financial strain & 2.71 & 2.20 & 0 & 9 \\
\hline Examination related strain & 6.00 & 2.19 & 0 & 9 \\
\hline Criminal victimization & 0.33 & 1.29 & 0 & 20 \\
\hline Anger & 1.77 & 2.34 & 0 & 9 \\
\hline Depression & 2.04 & 2.59 & 0 & 9 \\
\hline Bullying at Wave 1 & 1.30 & 2.02 & 0 & 12 \\
\hline Bullying at Wave 2 & 1.39 & 2.11 & 0 & 15 \\
\hline
\end{tabular}

Note: Total $N=655$.

measure whether close friends engaged in delinquent behaviors such as smoking, drinking, stealing money, and destroying property. Seven Likerttype items (ranging from $0=$ none to $4=$ all) captured the number of close friends involved in each act. A high score represents higher levels of association with delinquent peers and the measure ranges from 0 to 28 and has a Cronbach's alpha score of .84, indicating high reliability.

The legitimacy of violence index measured at Wave 1 is a summative index of five items. It measures whether the use of violence can be justified to defend one's rights, achieve respect, obtain fair treatment, resist exploitation, or avoid appearing weak. The response options for each item ranged from 1 (strongly disagree) to 4 (strongly agree). It was coded so that a higher score indicates a high level of belief in the legitimacy of violence. This measure has a Cronbach's alpha of .88 . 


\section{Strain and Negative Emotions (Anger and Depression)}

Six types of strain, all measured at Wave 1, were examined in the current study, and these are family conflict, emotional and physical punishment by parents and teachers, financial stress, examination-related stress, and criminal victimization. According to Agnew (2001), these strains have a significant impact on delinquency because they are more likely to have the characteristics of being unjust, high in magnitude, or associated with low social control. All scales were coded so that a higher score indicates a higher level of each strain.

The family conflict scale consisted of the sum of three items, which were adapted from Aseltine et al. (2000). It measures the extent of experience of verbal/physical conflict among family members as well as verbal/physical conflict between a respondent and parents. The response options ranged from 0 (never) to 3 (always). The Cronbach's alpha for the items was .75, indicating moderately high levels of reliability for this measure.

A four-item parents' emotional and physical punishment scale was adapted from Piquero and Sealock (2000). It measures the frequency of parents' emotional and physical punishment of the respondents, such as name calling, negative comparisons to others, and hitting or attempting to hit the respondent (Cronbach's alpha $=.72$ ). The response options ranged from 0 (never) to 4 (more than 10 times) of physical and emotional punishment.

The teachers' emotional and physical punishment scale measures the frequency of teachers' emotional and physical punishment of the respondents. The four items include respondent's reports of physical hitting, calling names, and negative comparisons with others by teachers. Response categories range from 0 (never) to 4 (more than 10 times). These items parallel those from the measurement for parental punishment, and the Cronbach's alpha is .76.

The financial strain scale was developed by summing three items that measured subjective financial status of respondents on a 4-point Likert-type scale. These items are "I am not satisfied with the amount of money I have," "My family has too little money for clothing or food," and "My family has not enough money to support me." The Cronbach's alpha is .62, which indicates a marginal level of reliability in this measure.

The examination-related strain scale was created by summing three Likerttype items with four response categories. These items capture the degree to which respondents feel stress related to studying for examinations and include "I feel a lot of stress about studying," "I am not satisfied with my grade," and "My parents stress studying too much." The Cronbach's alpha is .63 for this index, which indicates that it has a marginal level of reliability. 
The victimization scale was created by summing five items that tap respondent's or family members' victimization experience. ${ }^{2}$ The items include victimization with regard to theft, robbery, burglary, sexual assault, and physical assault. The response options ranged from 0 (never) to 3 (five times or more). The Cronbach's alpha is .64 , which indicates that it has marginal reliability.

Three items measure whether respondents have felt uncontrollable outbursts of temper, urges to beat and harm someone, or urges to break things. This summative anger scale was adapted from items used by Derogatis (1977). The depression scale was partially derived from the Center for Epidemiological Studies Depression Scale (CES-D). Three items asked youth to rate whether they felt sad, worthless, or depressed. Both summative scales range from zero to nine and have high reliability scores (Cronbach's alpha $=.89$ for both scales).

\section{Bullying as a Dependent Variable}

Previous research has employed various approaches to assess the prevalence of school bullying, with self-reports tending to be the preferred method (see Espelage and Swearer [2003] on measuring bullying). Using self-report surveys, many studies examined the prevalence of bullying by first providing the definition of bullying to respondents and then asking how often they engage in such behaviors (Salmivalli et al., 1996; Swearer, 2001). Others studies (Siann et al., 1994; Slee \& Rigby, 1993; Wong, 2004) assessed the prevalence of school bullying, categorizing students into bullies and victims. However, these traditional approaches to capturing school bullying have several potential limitations, possibly resulting in an inaccurate assessment of prevalence and frequency of this behavior (see, e.g., Bosworth et al., 1999; Espelage \& Swearer, 2003). First, respondents may be unwilling to view their behaviors toward fellow students as bullying, consequently underreporting their bullying. Second, it is possible that students simply do not consider their mischievous behaviors as bullying or causing any harm to other students. Third, simple categorization of students as bullies and victims ignores the dynamic and continuous aspects of bullying. Studies indicate that students engage in bullying in various roles including bullies, victims, bullies-victims, and observers. This simple dichotomous measurement of bullying may also exclude those who engage in bullying infrequently or subtly (Espelage \& Swearer, 2003). Another limitation in the previous research seeking to measure bullying is that many studies, especially in the United States, tend to focus on physical aggression while ignoring the measurement of psychological aggression (Bosworth et al., 1999). 
Table 2

Prevalence of Bullying Behaviors Among Korean Youth (in percentages)

\begin{tabular}{lcccc}
\hline & Never & $\begin{array}{c}1 \text { to 2 } \\
\text { Times }\end{array}$ & $\begin{array}{c}3 \text { to 5 } \\
\text { Times }\end{array}$ & $\begin{array}{c}\text { 6 or More } \\
\text { Times }\end{array}$ \\
\hline 1. I have hit or pushed other student(s) & 85 & 11 & 2 & 2 \\
2. I have teased other student(s) & 49 & 37 & 8 & 6 \\
3. I have gotten other student(s) into trouble & 80 & 16 & 3 & 1 \\
4. I have shoved or provoked other student(s) & 87 & 10 & 3 & 1 \\
5. I have tried to pick fights with other student(s) & 93 & 6 & 1 & 1 \\
\hline
\end{tabular}

Note: Total $N=655$.

Following Bosworth et al. (1999), the current study defined physical and psychological aggression to other students as bullying whether it occurs on or off school grounds. Bullying at Wave 2 was measured by asking how often respondents engaged in specific types of behaviors, which consist of both physical and emotional bullying. Five items, partially derived from Kim et al. (2005), were used to measure physical and psychological bullying. These items are (1) hitting or pushing others, (2) teasing others, (3) trying to pick fights with others, (4) getting others into trouble, and (5) shoving and provoking others. Items 1,3 , and 5 were frequently used in previous studies to measure aggressive deviant behaviors, and Items 2 and 4 were included to measure psychological aggression toward victims. These items are congruent with those used by Bosworth and colleagues (1999) to measure bullying. The response options ranged from 0 (never) to 3 (six or more times) and a summative index ranged from 0 to 15 for the five-item index. Table 2 indicates that only a small number of students in the sample engaged in physically aggressive bullying during the previous year but that nonphysical acts were much more prevalent in the year between waves.

Eighty-five percent of youth in the sample indicate that they did not hit or push fellow students, and 93\% reported no physical fighting with other student(s). However, about half of the students $(51 \%)$ indicated involvement in emotional and psychological bullying. These five items were combined to create a composite measure of bullying (Cronbach's alpha $=.77$ ).

\section{Control Variables}

Several sociodemographic factors known to have significant effects on bullying in previous research were used as control variables. Overall, studies have found that males are more likely than females to engage in bullying 
(e.g., Olweus, 1993; Seals \& Young, 2003), and physically dominant youths are more often involved in bullying (Olweus, 1991). In the current study, gender, physical strength, grade (academic achievement), and parental income were used as control variables.

Gender was dichotomized as a dummy variable, coding males as 1 and females as 0 . Respondents' height at Wave 1 was grouped into three categories: low height (below 154 centimeters), middle height (154 to 167 centimeters), and high height (over 167 centimeters). Sixteen percent of respondents in the sample were in the low-height group, $68 \%$ in the middle-height group, and $15 \%$ in the high-height group. The middle-height group was used as a reference. Each respondent's grade (academic achievement) in class was categorized into three dummy variables: high grade (1 to 10$)$, middle grade (11 to 25), and low grade (below 25). Thirty-one percent of respondents reported that their grades were between 1 and 10, 46\% between 11 and 25 , and $23 \%$ above 25 during the first wave. Those in the middle grade were used as a reference group. The monthly average for total income of both parents measured at the first wave was also used as a control variable and was divided into three categories: low income (less than $\$ 1,500$ a month), middle income (between $\$ 1,500$ and $\$ 3,500$ a month), and high income (more than $\$ 3,500$ a month). A majority of respondents $(61 \%)$ indicate that parents' monthly income was between $\$ 1,500$ and $\$ 3,500$, and this group was used as a reference. Twenty-three percent of respondents in the sample reported that their parents' monthly income was less than $\$ 1,500$, whereas $16 \%$ indicate parents' monthly income as more than $\$ 3,500$.

The control variables of income, height, and grades contained missing data on at least 1 item in 48 cases. Missing data were imputed through mean substitution for these items. No missing data imputation was used for any theoretical construct from the theories under consideration. Additionally, to better understand the causal effects of low self-control, differential association, and strain variables on bullying at Wave 2, bullying measured at Wave 1 was used as a control variable. This composite measure used four items identical to the Wave 2 bullying measure, but students were not asked whether they picked fights with others.

\section{Findings}

Table 3 presents the zero-order correlations between key independent variables and bullying. As expected, all the independent variables (except financial strain and depression) exhibit significant bivariate relationships 
Table 3

Correlation Matrix Among Major Independent and Dependent Variables

\begin{tabular}{|c|c|c|c|c|c|c|c|c|c|c|c|c|}
\hline & 1 & 2 & 3 & 4 & 5 & 6 & 7 & 8 & 9 & 10 & 11 & $\begin{array}{ll}12 & 13\end{array}$ \\
\hline 1. & 1 & & & & & & & & & & & \\
\hline 2. & $.30 * * *$ & 1 & & & & & & & & & & \\
\hline 3. & $.23 * * *$ & $.24 * * * 1$ & & & & & & & & & & \\
\hline 4. & $.27 * * *$ & $.13^{* *}$ & $.22 * * *$ & 1 & & & & & & & & \\
\hline 5. & $.15^{* * * *}$ & $.12 * *$ & $.16^{* * * *}$ & $.45^{* * * *}$ & 1 & & & & & & & \\
\hline 6. & $.18^{* * *}$ & $.17 * * *$ & $.27 * * *$ & $.25^{* * *}$ & $.33^{* * *}$ & 1 & & & & & & \\
\hline 7. & $.08 *$ & .04 & $.11 * *$ & $.19 * * *$ & $.16^{* * * *}$ & .06 & 1 & & & & & \\
\hline 8. & $.26 * * *$ & .07 & $.10 * *$ & $.31 * * *$ & $.31 * * *$ & $.22 * * *$ & .06 & 1 & & & & \\
\hline 9. & $.09^{*}$ & $.19 * * *$ & $.36^{* * *}$ & $.12 * *$ & $.10^{*}$ & $.18 * * *$ & $.12 * *$ & .04 & 1 & & & \\
\hline 10. & $.33 * * *$ & $.31 * * *$ & $.30^{* * * *}$ & $.26^{* * *}$ & $.24 * * *$ & $.16^{* * *}$ & $.08^{*}$ & $.18^{* * *}$ & $.21 * * *$ & 1 & & \\
\hline 11. & $.18 * * *$ & $.09^{*}$ & $.15^{* * *}$ & $.28 * * *$ & $.24 * * *$ & $.10 *$ & $.08^{*}$ & $.21 * * *$ & $.13 * *$ & $.57 * * *$ & 1 & \\
\hline 12. & $.26^{* * * *}$ & $.29 * * *$ & $.37 * * *$ & $.18^{* * *}$ & $.16^{* * *}$ & $.38 * * *$ & $.09^{*}$ & $.17 * * *$ & $.36 * * *$ & $.29 * * *$ & $.12 * *$ & 1 \\
\hline 13. & $.22 * * *$ & $.25^{* * * *}$ & $.19 * * *$ & $.13 * *$ & $.11^{* *}$ & $.30 * * *$ & .07 & $.15^{* * *}$ & $.16^{* * *}$ & $.14 * * *$ & .05 & $.51 * * * 1$ \\
\hline
\end{tabular}

Note: (1) low-self control, (2) legitimacy of violence, (3) association with delinquent peers, (4) family conflict, (5) parental punishment, (6) teachers' punishment, (7) financial strain, (8) examination-related strain, (9) criminal victimization, (10) anger, (11) depression, (12) bullying at Wave 1, and (13) bullying at Wave 2.

$* p<.05$. ** $p<.01 . * * * p<.001$ (two-tailed tests).

with bullying at Wave 2. Low self-control was significantly related to bullying in that those with low self-control are more likely to engage in bullying. The bivariate relationships between various strains and bullying were also significant. Those who experience higher levels of family conflict, parental punishment, or criminal victimization are more likely to engage in bullying. As expected, anger is significantly related to bullying, consistent with previous findings. The bivariate results also indicate that those who associate with delinquent peers or have positive attitudes toward violence are more likely to commit bullying. These bivariate results are consistent with extant research on delinquency. Below we further explore whether models based explicitly on criminological theories provide strong explanations of bullying behaviors.

Because the dependent variable for this analysis takes the form of an integer composed of the summary score from the five bullying items, ordinary least squares (OLS) model estimates could be misleading. This results from the skewed distribution of the dependent variable. The large number of zeroes-in this case $45 \%$ of the youth reported no bullying behaviors-make the use of OLS untenable (Long, 1997). The negative binomial and Poisson regression models have been successfully used in other tests of criminological 
theories that draw upon summarized ordinal composite scores of delinquency with similarly skewed distributions (e.g., Burt, Simons, \& Simons, 2006). The variance of the dependent variable exceeds the mean, which is a threshold indication for determining whether overdispersion is present and that negative binomial regression is preferred. Tests of the alpha coefficient embedded within the model estimation empirically confirmed the superior fit of the negative binomial model when compared to the Poisson models (Cameron \& Trivedi, 1998).

The models in Table 4 were estimated in STATA 8.0 and clustered on the school the youth attended. This yields a robust estimate of the standard errors, which is presented in Table 4 and corrects for the clustering of observations from the same school. The inclusion of the lagged dependent variable (bullying at Wave 1) in these models is an attempt to correct the models for stability in bullying behavior over time that could otherwise be misattributed to the theoretically specified variables.

Table 4 presents a baseline model, three models with measures that are congruent with the primary criminological theories presented, and a full model that includes the control variables and all theoretically relevant variables. At every step, control variables were included in the model. The findings indicate that bullying is a stable activity, at least in the space of the year between the two waves. The coefficient for bullying at Wave 1 is statistically significant and relatively stable across all five models. Similarly, the coefficient for male respondents indicates that they have much higher levels of bullying behavior than similarly situated female students. These two findings comport with the research on bullying as being somewhat stable (at least in the short run of 1 year between data collection points) and to be an area in which males exhibit more deviance than females. An unexpected finding was that higher income youths were more likely to participate in greater levels of bullying across all five models.

The second model, which includes the low self-control index, indicates that low self-control is significantly related to Wave 2 bullying. Those with low self-control are more likely to engage in bullying. However, low selfcontrol, although statistically significant in Model $2\left(\chi^{2}\right.$ change $=8.2,1 d f$, $p<.05$ ), provides only a modest overall improvement in the model.

The third model shows the effects of measures of differential association on Wave 2 bullying. The results indicate, consistent with expectations, that stronger beliefs about use of violence are positively associated with bullying. Contrary to our expectations, association with delinquent peers is not significantly related to bullying. The change in model fit from the baseline model is statistically significant $\left(\chi^{2}\right.$ change $\left.=6.3,2 d f, p<.05\right)$, indicating 
Table 4

Negative Binomial Regression Models of the Level of Wave 2 Bullying Behavior $(N=655)$

\begin{tabular}{|c|c|c|c|c|c|}
\hline & Base Model & Self Control & $\begin{array}{l}\text { Differential } \\
\text { Association }\end{array}$ & $\begin{array}{c}\text { General Strain } \\
\text { Theory }\end{array}$ & Full Model \\
\hline Bullying at Wave 1 & $\begin{array}{l}.186^{*} \\
(.060)\end{array}$ & $\begin{array}{l}.166^{*} \\
(.061)\end{array}$ & $\begin{array}{l}.168 * \\
(.040)\end{array}$ & $\begin{array}{l}.156^{*} \\
(.045)\end{array}$ & $\begin{array}{l}.144 * \\
(.035)\end{array}$ \\
\hline Males & $\begin{array}{l}.731 * \\
(.083)\end{array}$ & $\begin{array}{l}.754^{*} \\
(.094)\end{array}$ & $\begin{array}{l}.720 * \\
(.088)\end{array}$ & $\begin{array}{l}.793^{*} \\
(.142)\end{array}$ & $\begin{array}{l}.785^{*} \\
(.150)\end{array}$ \\
\hline Low height group & $\begin{array}{l}-.046 \\
(.195)\end{array}$ & $\begin{array}{l}-.056 \\
(.187)\end{array}$ & $\begin{array}{l}-.041 \\
(.208)\end{array}$ & $\begin{array}{l}-.017 \\
(.180)\end{array}$ & $\begin{array}{l}-.017 \\
(.187)\end{array}$ \\
\hline High height group & $\begin{array}{c}.181 \\
(.143)\end{array}$ & $\begin{array}{l}.170 \\
(.148)\end{array}$ & $\begin{array}{l}.161 \\
(.157)\end{array}$ & $\begin{array}{l}.185 \\
(.166)\end{array}$ & $\begin{array}{l}.160 \\
(.186)\end{array}$ \\
\hline High grade group & $\begin{array}{c}.059 \\
(.112)\end{array}$ & $\begin{array}{c}.082 \\
(.097)\end{array}$ & $\begin{array}{c}.049 \\
(.108)\end{array}$ & $\begin{array}{c}.116 \\
(.088)\end{array}$ & $\begin{array}{l}.115 \\
(.096)\end{array}$ \\
\hline Low grade group & $\begin{array}{l}.075^{*} \\
(.035)\end{array}$ & $\begin{array}{c}.075 \\
(.049)\end{array}$ & $\begin{array}{c}.052 \\
(.043)\end{array}$ & $\begin{array}{l}.087 * \\
(.022)\end{array}$ & $\begin{array}{c}.072 \\
(.046)\end{array}$ \\
\hline Low income group & $\begin{array}{l}-.168 \\
(.229)\end{array}$ & $\begin{array}{l}-.128 \\
(.222)\end{array}$ & $\begin{array}{l}-.143 \\
(.227)\end{array}$ & $\begin{array}{l}-.167 \\
(.211)\end{array}$ & $\begin{array}{l}-.129 \\
(.202)\end{array}$ \\
\hline High income group & $\begin{array}{c}.225^{*} \\
(.066)\end{array}$ & $\begin{array}{l}.222 * \\
(.075)\end{array}$ & $\begin{array}{l}.201 * \\
(.067)\end{array}$ & $\begin{array}{r}.253^{\dagger} \\
(.134)\end{array}$ & $\begin{array}{l}.238^{\dagger} \\
(.138)\end{array}$ \\
\hline Low self-control & & $\begin{array}{l}.014^{*} \\
(.003)\end{array}$ & & & $\begin{array}{c}.008 \\
(.005)\end{array}$ \\
\hline Legitimacy of violence & & & $\begin{array}{c}.027^{\dagger} \\
(.015)\end{array}$ & & $\begin{array}{c}.019 \\
(.018)\end{array}$ \\
\hline Association with delinquent peers & & & $\begin{array}{c}.016 \\
(.026)\end{array}$ & & $\begin{array}{c}.007 \\
(.031)\end{array}$ \\
\hline Family conflict & & & & $\begin{array}{c}.031 \\
(.032)\end{array}$ & $\begin{array}{c}.021 \\
(.039)\end{array}$ \\
\hline Parental punishment & & & & $\begin{array}{l}-.009 \\
(.029)\end{array}$ & $\begin{array}{l}-.007 \\
(.028)\end{array}$ \\
\hline Teachers' punishment & & & & $\begin{array}{c}.024 \\
(.018)\end{array}$ & $\begin{array}{c}.021^{\dagger} \\
(.013)\end{array}$ \\
\hline Financial strain & & & & $\begin{array}{c}.032 \\
(.059)\end{array}$ & $\begin{array}{l}.031 \\
(.057)\end{array}$ \\
\hline Examination-related strain & & & & $\begin{array}{l}.048^{*} \\
(.021)\end{array}$ & $\begin{array}{c}.040 \\
(.026)\end{array}$ \\
\hline Criminal victimization & & & & $\begin{array}{l}-.039 \\
(.072)\end{array}$ & $\begin{array}{l}-.040 \\
(.061)\end{array}$ \\
\hline Anger & & & & $\begin{array}{c}.011 \\
(.011)\end{array}$ & $\begin{array}{l}-.011 \\
(.021)\end{array}$ \\
\hline Depression & & & & $\begin{array}{l}.021 * \\
(.007)\end{array}$ & $\begin{array}{c}.025^{*} \\
(.005)\end{array}$ \\
\hline Constant & $\begin{array}{c}-0.483 * \\
(0.095)\end{array}$ & $\begin{array}{c}-1.226^{*} \\
(0.091)\end{array}$ & $\begin{array}{c}-0.725 * \\
(0.255)\end{array}$ & $\begin{array}{c}-1.039 * \\
(0.103)\end{array}$ & $\begin{array}{c}-1.540 * \\
(0.109)\end{array}$ \\
\hline $\operatorname{LR} \chi^{2}$ & $189.6^{*}$ & $197.8^{*}$ & $195.9 *$ & $205.9 *$ & $211.9 *$ \\
\hline$d f$ & 8 & 9 & 10 & 16 & 19 \\
\hline Nagelkerke $R^{2}$ & .26 & .27 & .26 & .28 & .29 \\
\hline
\end{tabular}

Note: Robust standard errors in parentheses.

$* p<.05$ (two-tailed test). $\dagger p<.05$ (one-tailed test). 
that the addition of this domain of independent variables yielded a better than chance improvement of model fit.

The fourth model examines the effects of strain-related variables on Wave 2 bullying. The results indicate that examination-related strain and depression have significant effects on Wave 2 bullying in the direction hypothesized. As perception of examination-related strain and depression increase so too do bullying behaviors. Similar to the differential association variables, measures of GST produced an overall improvement in model fit that was better than chance $\left(\chi^{2}\right.$ change $\left.=16.3,8 d f, p<.05\right)$.

To examine whether collectively these theoretical perspectives could significantly increase the understanding of the level of bullying, we estimated Model 5, which included all measures from all domains. Of the three theories, only GST maintained significant explanatory power in the model. Depression was significant, and teacher's punishment was marginally significant $(p<.05$, one-tailed test) in the full model. No other domain contributed a significant predictor of higher levels of bullying behavior. Nevertheless, model improvement statistics $\left(\chi^{2}\right.$ change $=22.3,11 d f, p<$ .05 ) did suggest these 11 measures offer more than a chance improvement of fit, but that is largely due to the power of GST's strain measures. The majority of explanatory power across all the models was contributed by the control variables included in the base model, and all theoretical domains contributed only modest improvements in explaining bullying behaviors within the sample (cf. Menard [2000] on a cautionary approach to these statistics as measures of model fit). More simply, knowledge of a youth's prior behavior and gender appear to be most useful in explaining the extent of involvement one has in bullying in this sample.

Regression diagnostics indicated that collinearity, which might be a concern in a model with numerous independent variables, was not an issue when variance inflation factors were calculated. Thus, with respect to that concern, the model is methodologically sound. Plotting of observed and predicted counts using Long and Freese's (2005) postestimation diagnostic routines indicated a very close correspondence between model predictions and observed outcomes increasing confidence in model fit.

One question that is logical to ask is, Does the inclusion of Wave 1 bullying reduce the remaining variance that can be explained to a very low level and therefore account for the theories having a poor fit in these models? To examine this we estimated the full model (not shown) of only the theoretical domains without bullying at Wave 1 . That model yielded significant coefficients in the expected directions for low self-control, teacher punishment, and examination-related strain. The significant findings regarding 
school-based effects on bullying are consistent with the findings in Models 4 and 5. Additionally, it is unsurprising that, when bullying at Wave 1 is removed, low self-control, with which it is significantly correlated $(r=.26)$, has a significant direct effect on bullying at Wave 2. Nevertheless, the limited overall explanatory power of the three general theories' key variables is still apparent in that model.

\section{Discussion and Conclusion}

Previous research indicates that school bullying is a global phenomenon that has damaging psychological and physical effects on victims and bullies alike. Nevertheless there have been few efforts directed at testing the fit of criminological theories as explanations of school bullying. Below we first summarize how the current research has filled this gap using a unique longitudinal sample of Korean youth and a set of independent measures derived from the most recent criminological research. Second, some consideration of policy implications that may not necessarily be generalized beyond the Korean school experience will be discussed. Finally we consider the future directions for strengthening the link between criminology and school bullying through further empirical work.

With respect to the utility of traditional theories as an explanation of bullying, the initial zero-order correlations offered support for this line of research. Those correlations indicated that, consonant with our reading of the literature, measures derived from traditional criminological theory had a good "fit" with the bullying phenomenon. Further exploration of this relationship, however, indicates those theories have relatively little unique explanatory power. The multivariate tests that incorporated theoretically specified measures failed to offer substantial improvement from naïve baseline models.

Regarding the applicability of a general theory of crime to school bullying, the results indicate a weak impact of low self-control theory on bullying. Consistent with the general theory of crime, low self-control (measured at Wave 1) was significantly related to bullying at Wave 2 in the bivariate analyses and in the model testing low self-control, but its significant effect on bullying disappears in the final full model. This result is unexpected in a sense that a low self-control theory was originally developed to explain not only criminal behaviors but also analogous behaviors to crime such as gambling, smoking, and prostitution (Gottfredson \& Hirschi, 1990). Previous studies (Arneklev, Grasmick, Tittle, \& Bursik, 1993; Cochran, Wood, Sellers, Wilkerson, \& Chamlin, 1998) that examined the relationship between low 
self-control and various analogous behaviors (i.e., academic dishonesty, accidents) provided strong support for the generalizability of the theory to a variety of behaviors. Though numerous studies examined the key propositions of low self-control theory, relatively few studies explored the relative effect of low self-control on criminal and analogous behaviors, after including other criminological perspectives (Baron, 2003). Additionally the current study's omission of opportunity may contribute to the weakness of the test of Gottfredson and Hirschi's (1990) theory as well. The close correlation of low self-control with prior bullying also represents a temporal ordering issue that must be disentangled in future research.

Similarly the findings reveal that differential association theory offers little power to explain the extent of school bullying. Students' attitudes toward the use of violence were a significant predictor of bullying in the baseline model to testing differential association, but the effect on bullying disappears with the inclusion of variables from competing theoretical perspectives. It also indicates no significant relationship between association with delinquent peers and bullying in both baseline and full models. These findings are somewhat unexpected, considering that bullying is often conceived of as a group phenomenon in the previous research and that the Korean society has maintained a high level of collective culture, which promotes group-oriented behaviors. Unlike previous research that examined the effect of bully association on bullying, we included delinquent peer association and explored its effect on bullying. It may be that this approach to measurement impacts the findings as bully's friendship patterns may differ from those of delinquents who engage in more serious antisocial behaviors. Also, a partial test of differential association theory (see Bruinsma [1992] for a comprehensive test of differential association theory) may have resulted in a weak explanatory power of the theory with respect to bullying in the present test.

Our findings show relatively modest support for the applicability of GST in explaining bullying. Two of eight GST-related variables (either in the baseline model or the final model) were significantly related to bullying, though there were differences in the significant strains in the final model. Contrary to previous findings, the results indicate that parental punishment and family conflicts were not significantly related to bullying. Criminal victimization experience, which was found to be a strong predictor of delinquency, was, likewise, not significantly related to school bullying in the current study. However, the most interesting finding is that teachers' emotional and physical punishment and examination-related strain have significant effects on the Wave 2 bullying. Those who experienced a high level of examination-related strain and experienced emotional and physical punishment by teachers are 
more likely to engage in bullying, even after controlling the effects of the Wave 1 bullying and other theoretically informed measures. These findings indicate that school-generated strains have significant effects on bullying. Overall, compared to students in the United States, Korean students are known to experience very high levels of stress because of the competitive college entrance examination, the process of preparing for these examinations (commonly referred to as "examination hell"), and the negative relationship with teachers (Cho, 1995; M. Lee \& Larson, 2000). ${ }^{3}$ Korean teachers also have a significant (positive or negative) impact on students for several reasons. Korean teachers' relationship with students is accepted as an extension of parent-child relationship in many Asian countries, including South Korea (Yu \& Yang, 1994). Students spend a significant amount of time with their teachers on the highly valued goal of achieving success in education. Most significantly, the teachers' physical and emotional punishment had been tolerated and allowed in the name of the "whip of love," believing that punishment is necessary to discipline students in school. However, excessive emphasis on academic achievement, frequent physical and emotional punishment by teachers, and increased awareness of individualism among students have contributed to a negative relationship between students and teachers and is a significant source of strain to Korean students (see, e.g., Moon \& Morash, 2004).

Interestingly, depression was positively and significantly related to the Wave 2 bullying. Several studies indicate that depression is related to aggressive behaviors to a certain degree (Seligman, 1975; Shamoo \& Patros, 1990), which in turn may lead to bullying others. Depressed individuals typically exhibit pessimistic views of themselves and others and are more likely to engage in self-destructive deviant behaviors (i.e., taking illegal drugs, running away) and/or aggressive behaviors (i.e., bullying) toward others (Roland, 2002).

However, the current study indicates no significant effect of anger on bullying. A possible explanation is the measurement of trait-based (dispositional) negative emotions in this study rather than situational-based negative emotions. Trait-based negative emotions were employed, based on the common assumption that individuals with a persistent trait of reporting negative emotions are more likely to experience negative emotions in response to strains (see Mazerolle et al., 2003). To better understand the relationship between negative emotions and bullying, future research is needed to measure and examine the effect of situational-based negative emotions in response to strains on bullying. 
Although further research is needed to explore the etiology of bullying and intervention programs in reducing school bullying, it is important to note that the two statistically significant effects on bullying are isolated to strains located within the school environment. These findings indicate the necessity of finding ways to reduce the stress students experience from competitive examinations and of nurturing a positive student-teacher relationship. This has interesting consequences for policy: If school-based practices exacerbate school-based problems, then finding solutions within schools to ameliorate this issue is a possibility. School authorities and teachers need to recognize the negative consequences of excessive amount of examination-related strain and ineffective physical and emotional punishment and find alternative disciplinary methods that do not include ineffective, and potentially damaging, emotional and physical abuse. Otherwise teachers, who should play a critical role in preventing and reducing bullying, may inadvertently exacerbate it.

Overall, the results indicate these three criminological theories offer limited explanations of bullying in this sample. That theoretically informed measures have little explanatory power is surprising and disappointing. This leads to questions of whether traditional criminological theory is adequate to the task of predicting bullying or whether criminologists might profit by developing bullying-specific theories. We argue that more research is necessary to further assess the generality of traditional criminology theories with adequate measurements of theoretically informed variables and understand the causes of school bullying. The current research offers an opportunity to sharpen future queries regarding bullying as well as to consider other theoretical avenues as explanatory frameworks for this phenomenon.

Future research, for example, should explore the gender difference in school bullying, as the current findings reveal that gender is significantly related to bullying in all the models. It may be interesting to examine whether traditional criminology theories, which were developed for more serious behaviors, especially male misbehaviors, can explain girls' bullying — which may be qualitatively different from boys' bullying. Because the current findings indicate the significant effects of school-generated strains on bullying, future research should seek to identify and measure various types of strains students experience in the context of school environment. Additionally, the breadth of criminological theory should be scanned for theories that have a promising fit with this phenomenon. We chose three theories that were general and appeared to have empirical support in the bullying literature as a starting point. This should not constrain future research from developing explanations from other theoretical traditions. 


\section{Notes}

1. This work was supported by the Korea Research Foundation Grant funded by the Korean Government (MOEHRD) (KRF-2006-332-B00265) for the second author.

2. In items for the criminal victimization scale, we asked whether victimization of various types of crime occurred to respondents as well as their family members. We recognize that the experience of one's own criminal victimization is different from those of his or her family's criminal victimization. An individual is more likely to experience negative emotions (i.e., anger) in response to his or her own criminal victimization, compared to his or her family's criminal victimization. However, the current measurement of criminal victimization is less problematic in the context of a collective culture in South Korea. A collective culture strongly emphasizes close family ties, collective responsibility, mutual trust, and interdependence among family members. Therefore, a member of the family is very concerned about the wellbeing of other family members and is likely to have a strong emotional response when a member of his or her family is criminally victimized.

3. Though there are positive aspects of the Korean educational system, we only focused on the negative side here to illustrate the stress Korean students have to endure. We hope that Western readers do not acquire bias against the educational system in South Korea because of the emphasis of this article on the negative aspects of the Korean educational system.

\section{References}

Agnew, R. (1992). Foundation for a general strain theory of crime and delinquency. Criminology, 30, 47-87.

Agnew, R. (2001). Building on the foundation of general strain theory: Specifying the types of strain most likely to lead to crime and delinquency. Journal of Research in Crime and Delinquency, 38, 319-361.

Agnew, R., Brezina, T., Wright, J. P., \& Cullen, F. T. (2002). Strain, personality traits, and delinquency: Extending general strain theory. Criminology, 40, 43-71.

Arneklev, B. J., Grasmick, H. G., Tittle, C. R., \& Bursik, R. J. (1993). Low self-control and imprudent behavior. Journal of Quantitative Criminology, 9, 225-247.

Aseltine, R. H., Gore, S., \& Gordon, J. (2000). Life stress, anger and anxiety, and delinquency: An empirical test of general strain theory. Journal of Health and Social Behavior, 41, 256-275.

Baldry, A. C., \& Farrington, D. P. (2000). Bullies and delinquents: Personal characteristics and parental styles. Journal of Community \& Applied Social Psychology, 10, 17-31.

Baron, S. W. (2003). Self-control, social consequences, and criminal behavior: Street youth and the general theory of crime. Journal of Research in Crime and Delinquency, 40, 403-425.

Batsche, G. M., \& Knoff, H. M. (1994). Bullies and their victims: Understanding a pervasive problem in the schools. School Psychology Review, 23, 165-174.

BBC. (2007). Bodyguards deter S. Korea bullies. Retrieved March 12, 2007, from http://news .bbc.co.uk/2/hi/asia-pacific/6400015.stm

Bosworth, K., Espelage, D. L., \& Simon, T. R. (1999). Factors associated with bullying behavior in middle school students. Journal of Early Adolescence, 19, 341-362.

Browne, K., \& Falshaw, L. (1996). Factors related to bullying in secure accommodation. Child Abuse Review, 5, 123-127.

Bruinsma, G. J. N. (1992). Differential association theory reconsidered: An extension and its empirical test. Journal of Quantitative Criminology, 8, 29-49. 
Burt, C. H., Simons, R. L., \& Simons, L. G. (2006). A longitudinal test of the effects of parenting and the stability of self-concept: Negative evidence for the general theory of crime. Criminology, 44, 353-396.

Cameron, A. C., \& Trivedi, P. K. (1998). Regression analysis of count data. New York: Cambridge University Press.

Cheongju Statistical Yearbook. (2005). Juvenile delinquency. Retrieved September 6, 2007, from http://stat.cjcity.net/homepage/statistical_sub04.htm

Cho, H. (1995). Children in the examination of war in South Korea: A cultural analysis. In S. Stephens (Ed.), Children and the politics of culture. Princeton, NJ: Princeton University Press.

Cochran, J. K., Wood, P. B., Sellers, C. S., Wilkerson, W., \& Chamlin, M. B. (1998). Academic dishonesty and low self-control: An empirical test of a general theory of crime. Deviant Behavior, 19, 227-255.

Derogatis, L. (1977). SCL 90: Administration, scoring, and procedures manual for the revised version. Baltimore: Johns Hopkins University.

Elliott, D. S., \& Menard, S. (1996). Delinquent friends and delinquent behavior: Temporal and developmental patterns. In D. Hawkins (Ed.), Delinquency and crime: Current theories. Cambridge: Cambridge University Press.

Endresen, I. M., \& Olweus, D. (2001). Self-reported empathy in Norwegian adolescents: Sex differences, age trends, and relationship to bullying. In A. C. Bohart, C. Arthur, \& D. J. Stipek (Eds.), Constructive \& destructive behavior: Implications for family, school, and society. Washington, DC: American Psychological Association.

Espelage, D. L., Bosworth, K., \& Simon, T. R. (2000). Examining the social context of bullying behaviors in early adolescence. Journal of Counseling \& Development, 78, 326-333.

Espelage, D. L., \& Swearer, S. M. (2003). Research on school bullying and victimization: What have we learned and where do we go from here? School Psychology Review, 32, 365-383.

Farrington, D. P. (1991). Childhood aggression and adult violence: Early precursors and laterlife outcomes. In D. J. Pepler \& K. H. Rubin (Eds.), The development and treatment of childhood aggression. Hillsdale, NJ: Erlbaum.

Korea Times. (2005). Females outnumber males. Retrieved September 7, 2007, from http://blog.naver.com/skader/80020548991

Gottfredson, M. R., \& Hirschi, T. 1990. A general theory of crime. Stanford, CA: Stanford University Press.

Grasmick, H., Tittle, C., Bursik, R. J., \& Arneklev, B. J. (1993). Testing the core empirical implications of Gottfredson and Hirschi's general theory of crime. Journal of Research in Crime and Delinquency, 30, 5-29.

Greenbaum, S., Turner, B., \& Stephens, R. D. (1988). Set straight on bullies. Los Angeles: Pepperdine University Press.

Gumi Statistical Yearbook. (2005). Juvenile delinquency. Available from http://gumi.go.kr/ tonggye/2005/02/02_15_13.html

HanKokilbo. (2007). Comparison of poverty rate among 16 metropolitan cities and provinces. Retrieved September 5, 2007, from http://blog.daum.net/virtualimage/10769421

Hay, C. (2001). Parenting, self-control, and delinquency: A test of self-control theory. Criminology, 39, 707-736.

Incheon Statistical Yearbook. (2005). Juvenile delinquency. Retrieved September 7, 2007, from http://www.incheon.go.kr/statistics/html_2005/html2005/index.html

Kim, E. J., Kim, I., \& Jung, T. (2001). Psychological vulnerabilities victimization at school bullying. Korean Journal of Clinical Psychology, 20, 245-257. 
Kim, Y. S., Koh, Y., \& Leventhal, B. L. (2005). School bullying and suicidal risk in Korean middle school students. Pediatrics, 115, 357-363.

Korean Educational Development Institute. (1998). A study on school bullying. Seoul: Author.

Korean Institute of Criminal Justice Policy. (1997). The actual condition and the preventing plans for school violence. Seoul: Author.

Korean Statistical Information Service. (2007a). Crime, accidents, and calamities. Retrieved September 7, 2007, from http://www.kosis.kr/eng/e_kosis.jsp?listid=S\&lanType=ENG

Korean Statistical Information Service. (2007b). Education, culture, and science. Retrieved September 7, 2007, from http://www.kosis.kr/eng/e_kosis.jsp?listid=P\&lanType=ENG

LaGrange, T. C., \& Silverman, R. A. (1999). Low self-control and opportunity: Testing the general theory of crime as an explanation for gender differences in delinquency. Criminology, 37, 41-72.

Lee, M., \& Larson, R. (2000). The Korean "examination hell": Long hours of studying, distress, and depression. Journal of Youth and Adolescence, 29, 249-271.

Lee, S. G. (2005). Effects of eco-systemic factors on peer violence at middle schools. Journal of the Korean Society of Child Welfare, 19, 141-170.

Loeber, R., \& Dishion, T. (1983). Early predictors of male delinquency: A review. Psychological Bulletin, 94, 68-99.

Long, J. S. (1997). Regression models for categorical and limited dependent variables. London: Sage.

Long, J. S., \& Freese, J. (2005). Regression models for categorical outcomes using Stata. College Station, TX: Stata Press.

Lowenstein, L. F. (1978). Who is the bully? Bulletin of the British Psychological Society, 31, 147-149.

Ma, X. (2001). Bullying and being bullied: To what extent are bullies also victims? American Educational Research Journal, 38, 351-370.

Mazerolle, P., \& Maahs, J. (2000). General strain and delinquency: An alternative examination of conditioning influences. Justice Quarterly, 17, 753-778.

Mazerolle, P., \& Piquero, A. (1997). Violent responses to strain: An examination of conditioning influences. Violence and Victims, 12, 323-343.

Mazerolle, P., Piquero, A., \& Capowich, G. E. (2003). Examining the links between strain, situational and dispositional anger, and crime: Further specifying and testing general strain theory. Youth \& Society, 35, 131-157.

Menard, S. (2000). Coefficients of determination for multiple logistic regression analysis. The American Statistician, 54, 17-24.

Ministry of Education and Human Resources Development. (2007). Education system. Retrieved September 7, 2007, from http://english.moe.go.kr/main.jsp?idx=020101

Mitchell, O., \& MacKenzie, D. L. (2006). The stability and resiliency of self-control in a sample of incarcerated offender. Crime \& Delinquency, 52, 432-449.

Moon, B., \& Morash, M. (2004). Adaptation of theory for alternative cultural contexts: Agnew's general strain theory in South Korea. Journal of International and Comparative Criminal Justice, 28, 77-104.

Nansel, T. R., Overpeck, M., Pilla, R. S., Ruan, W. J., Simons-Morton, B., \& Scheidt, P. (2001). Bullying behaviors among US youth: Prevalence and association with psychosocial adjustment. Journal of the American Medical Association, 285, 2094-2100.

National Youth Commission. (2003). School violence findings through the Internet in the first six months of 2003 (1 January 2003-30 June 2003). Seoul, South Korea: National Youth Commission.

Olweus, D. (1978). Aggression in the schools: Bullies and whipping boys. New York: John Wiley. 
Olweus, D. (1991). Bully/victim problems among school children: Basic facts and effects of a school-based intervention program. In K. Rubin \& D. Pepler (Eds.), The development and treatment of childhood aggression. Hillsdale, NJ: Lawrence Erlbaum.

Olweus, D. (1993). Bully/victim problems among school-children: Long-term consequences and an effective intervention program. In S. Hodgins (Ed.), Mental disorder and crime. Thousand Oaks, CA: Sage.

Olweus, D. (1994). Bullying at school: Long-term outcomes for the victims and an effective school-based intervention program. In L. R. Huesmann (Ed.), Aggressive behavior: Current perspectives. New York: Plenum.

Pepler, D. J., \& Craig, W. M. (1995). A peek behind the fence: Naturalistic observations of aggressive children with remote audiovisual recording. Developmental Psychology, 31, 548-553.

Peterson, J. S., \& Ray, K. E. (2006). Bullying and the gifted: Victims, perpetrators, prevalence, and effects. Gifted Child Quarterly, 50, 148-168.

Piquero, N. L., \& Sealock, M. D. (2000). Generalizing general strain theory: An examination of an offending population. Justice Quarterly, 17, 449-484.

Pratt, T. C., \& Cullen, F. T. (2000). The empirical status of Gottfredson and Hirschi's general theory of crime: A meta-analysis. Criminology, 38, 931-964.

Rigby, K., \& Slee, P. T. (1991). Bullying among Australian school children: Reported behavior and attitudes towards victims. Journal of Social Psychology, 131, 615-627.

Rigby, K., \& Slee, P. T. (1999). Suicidal ideation among adolescent school children, involvement in bully/victim problems and perceived low social support. Suicide and Life-Threatening Behavior, 29, 119-130.

Roland, E. (2002). Aggression, depression, and bullying others. Aggressive Behavior, 28, 198-206.

Salmivalli, C., Lagerspetz, K., Bjorkqvist, K., Osterman, K., \& Kaukiainen, A. (1996). Bullying as a group process: Participant roles and their relations to social status within the group. Aggressive Behavior, 22, 1-15.

Salmon, G., James, A., Cassidy, E. L., \& Javaloyes, M. A. (2000). Bullying a review: Presentation to an adolescent psychiatric service and within a school for emotionally and behaviourally disturbed children. Clinical Child Psychology and Psychiatry, 5, 563-579.

Seals, D., \& Young, J. (2003). Bullying and victimization: Prevalence and relationship to gender, grade level, ethnicity, self-esteem, and depression. Adolescence, 38, 735-747.

Seligman, M. (1975). Helplessness: on depression, development and death. San Francisco: Freeman.

Seo, M. J., \& Kim, K. Y. (2004). Personality and environmental characteristics of children who are bullies and/or victims. Korean Journal of Child Studies, 25, 93-108.

Shamoo, T., \& Patros, P. (1990). Helping your child cope with depression and suicidal thoughts. San Francisco: Jossey-Bass.

Siann, G., Callaghan, M., Glissov, P., Lockhart, R., \& Rawson, L. (1994). Who gets bullied? The effect of school, gender, and ethnic group. Educational Research, 36, 123-134.

Simons, R. L., Wu, C., Conger, R. D., \& Lorenz, F. O. (1994). Two routes to delinquency: Differences between early and late starters in the impact of parenting and deviant peers. Criminology, 32, 247-275.

Slee, P. T., \& Rigby, K. (1993). The relationship of Eysenck's personality factors and self-esteem to bully-victim behaviors in Australia. Personality and Individual Differences, 14, 371-373.

Smith, P. K., \& Brian, P. (2000). Bullying in school: Lessons from two decades of research. Aggressive Behavior, 26, 1-9.

Sutherland, E. (1947). Principles of criminology. Philadelphia: J. B. Lippincott. 
Swearer, S. M. (2001). Bullying survey—Youth version (BSY). Unpublished manuscript, University of Nebraska-Lincoln.

U.S. Department of State. (2007). Background note: South Korea. Retrieved September 2, 2007, from http://www.state.gov/r/pa/ei/bgn/2800.htm

Warr, M. (2005). Making delinquent friends: Adult supervision and children's affiliations. Criminology, 43, 77-105.

Wong, D. (2004). School bullying and tackling strategies in Hong Kong. International Journal of Offender Therapy and Comparative Criminology, 48, 537-553.

Yang, J. H. (2004). The factors related to the bullying behavior of middle school students. In The 1st Conference of the Korean Youth Panel Study (pp. 65-85). Seoul, South Korea: National Youth Policy Institute.

Yu, A. B., \& Yang, K. S. (1994). The nature of achievement motivation in collectivist societies. In U. Kim, H. C. Triandis, C. Kagichibase, S. C. Choi, \& G. Yoon (Eds.), Individualism and collectivism: Theory, method, and applications. Thousand Oaks, CA: Sage.

Byongook Moon is an assistant professor in the Department of Criminal Justice at the University of Texas at San Antonio. He was a graduate of the School of Criminal Justice, Michigan State University, in 2004. His research focuses on the application of general strain theory to explaining delinquency and bullying in South Korea. He also has been involved in research on stress, cyber deviant behaviors, and domestic violence. Recent publications appear in Youth \& Society, Crime \& Delinquency, and Journal of Criminal Justice.

Hye-Won Hwang is an assistant professor in social welfare at the Cheongju University in South Korea. She is a graduate of the College of Human Ecology, Michigan State University. Her research has focused on the healthy development of South Korean youth and finding effective intervention strategies for improving their quality of lives. She has been especially involved in research on a longitudinal study for understanding the delinquent behavior of South Korean youth and the monitoring of UN CRC implementation in Korea. Recent publications appear in Journal of Korean Council for Children's Rights, Korea Journal of Youth Studies, Journal of the Korean Society of Child Welfare, and International Journal of Human Ecology.

John D. McCluskey is an associate professor in the Department of Criminal Justice at the University of Texas at San Antonio. His recent research has appeared in Justice Quarterly, Crime \& Delinquency, and Journal of Criminal Justice on the topics of policing, delinquency, and violence. 